\title{
Cytochrome P450 2D5
}

National Cancer Institute

\section{Source}

National Cancer Institute. Cytochrome P450 2D5. NCI Thesaurus. Code C19283.

Cytochrome P450 2D5 is a rat liver ER membrane-bound heme-thiolate monooxygenase, involved in an NADPH-dependent electron transport pathway that oxidizes various compounds, including steroids, fatty acids, and xenobiotics. Expression is induced in liver and other tissues by drugs, pesticides, and carcinogens. 